Supplement of Atmos. Chem. Phys., 19, 14967-14977, 2019

https://doi.org/10.5194/acp-19-14967-2019-supplement

(C) Author(s) 2019. This work is distributed under

the Creative Commons Attribution 4.0 License.

(c) (i)

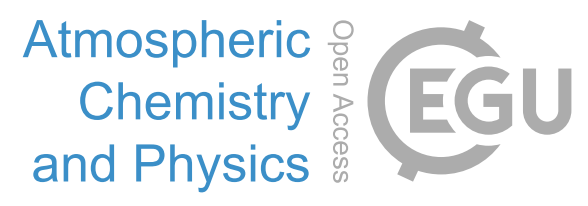

Supplement of

\title{
Evaluation of hygroscopic cloud seeding in liquid-water clouds: a feasibility study
}

Fei Wang et al.

Correspondence to: Zhanqing Li (zli@atmos.umd.edu)

The copyright of individual parts of the supplement might differ from the CC BY 4.0 License. 


\section{Vertical structure of clouds from sounding data and its uncertainties}

In this study, we use RH profiles, derived from sounding data, to analyze the vertical structure of clouds. First of all, the accuracy of RH from radiosonde observation is particularly important. The L-band sounding system, measured once per second, was widely used in operational radiosonde stations in China since 2002 (Zhang et al., 2016; Guo et al., 2016). The GTS1 digital electronic sensor, one of the key components of the L-band sounding system, provides fine-resolution profiles of temperature, pressure, $\mathrm{RH}$, wind speed and direction at least twice a day to monitor the vertical profiles of atmospheric thermodynamic condition. Comparisons between GTS1 and Vaisala RS80 from previous studies indicated adequate agreement in the profile measurements in the troposphere, but a lot larger biases in the upper atmosphere (Bian et al., 2011). Compared with Vaisala RS92, GTS1 sensor was found to yield a systematic dry bias in the order of $10 \%$ below $500 \mathrm{hPa}$. The GTS1 sensor showed a delayed response or a lag effect after the humidity changes rapidly like going through a cloud layer (Li et al., 2009).

Accurate identification of clouds by using sounding data is also import to this study. The method we choose may seriously affect the result. Three widely used algorithms have been employed to determine the locations of cloud layers from radiosonde observations, including:

a. Dewpoint temperature depressions below certain threshold (Poore et al., 1995);

b. Cloud detection method based on T (z) and RH (z), which are the second-order derivatives of temperature and RH with respect to height, respectively (Chernykh and Eskridge, 1996).

c. RH thresholding method (Wang and Rossow, 1995), i.e. $\mathrm{RH}_{\max }>87 \%, \mathrm{RH}_{\min }>84 \%$, a $\mathrm{RH}$ jump at cloud base and cloud top; (here after WR95)

The main uncertainty of WR95 method is that it tends to misclassify moist, cloud-free layers as clouds. To avoid this, an improved algorithm was proposed by using W-band cloud radar, ceilometer and satellite observation (Wang et al., 1999;Zhang et al., 2010). In this study we use the WR95 method to determine cloud vertical structure, with the RH threshold being set to $>84 \%$ according to the findings from previous inter-comparison studies (Zhou and Ou, 2010).

To study vertical structure of cloud layer and the wind field at seeding altitude, radiosonde data including Shanghai $\left(121.44^{\circ} \mathrm{E}, 31.40^{\circ} \mathrm{N} ; \sim 150 \mathrm{~km}\right.$ north of the experiment area), Hangzhou $\left(120.16^{\circ} \mathrm{E}, 30.25^{\circ} \mathrm{N}\right.$; $\sim 150 \mathrm{~km}$ west of the experiment area), and Taizhou $\left(121.41^{\circ} \mathrm{E}, 28.62^{\circ} \mathrm{N} ; \sim 150 \mathrm{~km}\right.$ south of the experiment area) were analyzed at 0600 UTC on 4 September 2016. The cloud showed apparently double-layer structure over the experimental region. The upper-layer cloud of $8 \sim 12 \mathrm{~km}$ height was dominated by west wind, however, the easterly wave cloud, which mainly blow $\sim 4 \mathrm{~km}$ height, was dominated by east wind.
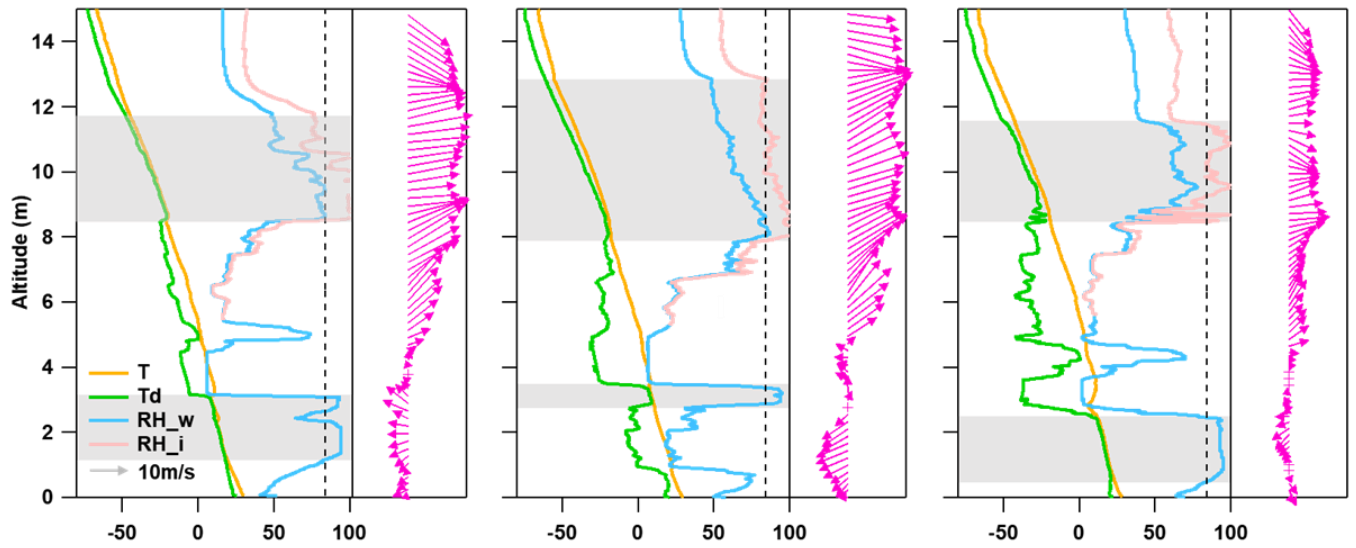

Figure S1. Vertical profiles of temperature $(T)$, dew-point temperature $\left(T_{d}\right)$, relative humidity $(R H)$, wind 
speed and direction from radiosonde measurements over Hangzhou $\left(120.16^{\circ} \mathrm{E}, 30.25^{\circ} \mathrm{N} ; \sim 150 \mathrm{~km}\right.$ west of the experiment area), Shanghai $\left(121.44^{\circ} \mathrm{E}, 31.40^{\circ} \mathrm{N} ; \sim 150 \mathrm{~km}\right.$ north of the experiment area), and Taizhou ( $121.41^{\circ} \mathrm{E}, 28.62^{\circ} \mathrm{N} ; \sim 150 \mathrm{~km}$ south of the experiment area) at $0600 \mathrm{UTC}$ on 4 September. Dot lines defined a threshold of $84 \%$ given by Wang and Rossow (1995), and the gray shaded area indicate cloud region which identified by RH threshold.

\section{TREC technique description}

The TREC method begins by subdividing the radar scan of Domain $\mathrm{C}$ into equal boxes with each box spaced some distance apart. The initial boxes are then correlated with all possible arrays of the same size in the second scan to find the best matching second box. The motion vector over a box is assumed to be uniform and is determined by calculating the maximum correlation coefficient $\left(R_{\max }\right)$ between two consecutive reflectivity boxes (Tuttle and Foote, 1990). The correlation coefficient $(R)$ is then calculated using the following formula:

$R=\frac{\sum_{x, y} Z_{1}(x, y) Z_{2}(x, y)-\frac{1}{N} \sum_{x, y} Z_{1}(x, y) \sum_{x, y} Z_{2}(x, y)}{\left\{\left[\sum_{x, y} Z_{1}^{2}(x, y)-N \overline{Z_{1}^{2}}\right] \times\left[\sum_{x, y} Z_{2}^{2}(x, y)-N \overline{Z_{2}^{2}}\right]\right\}^{\frac{1}{2}}}$,

where $Z_{1}(x, y)$ and $Z_{2}(x, y)$ represent the reflectivity arrays at times $\mathrm{t}_{0}$ and $\mathrm{t}_{1}, \bar{Z}_{1}$ and $\bar{Z}_{2}$ represent the mean reflectivity values of the box, and $N$ indicates the number of data points within a box. A search radius $R=v_{\max } \times t$, where $v_{\max }$ is the maximum velocity of the target echo, is used to limit the greatest displacement. According to the continuity of the echo development, the TREC method uses a correlation analysis to calculate the relative movement between successive boxes. The mean direction of the seeded echoes (Domain C) is estimated by averaging all TREC vectors of each box with in the domain identified by threshold reflectivity.

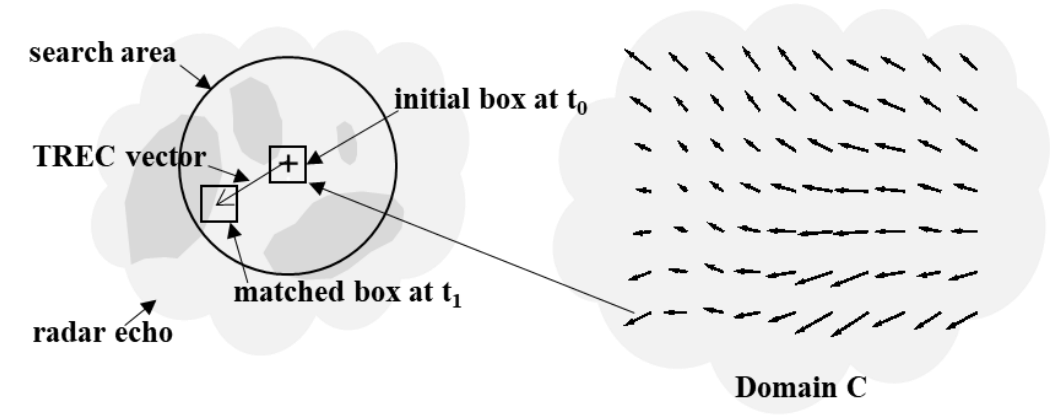

Figure S2. Schematic illustration shows the computation of a TREC vector to determine the motion of the Domain $\mathrm{C}$ which identified by threshold reflectivity. The box at time $t_{0}$ is compared to all boxes of the same size at a later time $t_{1}$ that appear within a circular search area. The position of the matched box for which the correlation coefficient reaches a maximum determines the end point of the motion vector.

\section{Motion of the seeding echo}

We tracked the seeding echoes frame by frame to analysis the variation caused by cloud seeding. As the seeding operation continued, radar parameters including $C R$ and VIL gradually decreased. About 12 min after seeding ended (0418 UTC), $C R$ decreased to a minimum ( $\sim 10 \mathrm{dBz}$ ) and $V I L$ was $\sim 0.2 \mathrm{~kg} \mathrm{~m}^{-3}$. 


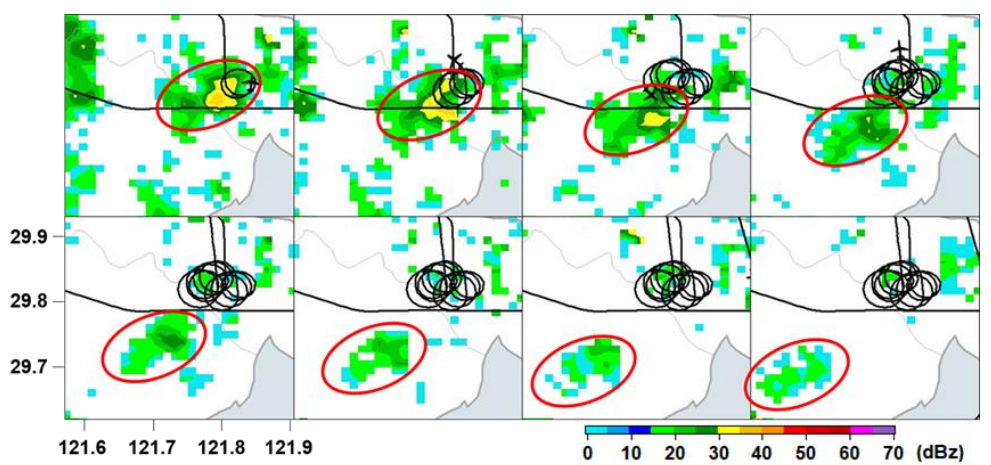

Figure S3. Composite reflectivity (5 layers grids data at 1000 3000m intervals of $500 \mathrm{~m}$ ) of seeding echo at $0336 \sim 0418$ UTC ( 6 min intervals), The red oval outlines the seeding clouds. The red oval outlines the seeding cloud and the black lines represent flight track. To clearly show seeding cloud, weak echoes $(<10 \mathrm{dBz})$ are rejected.

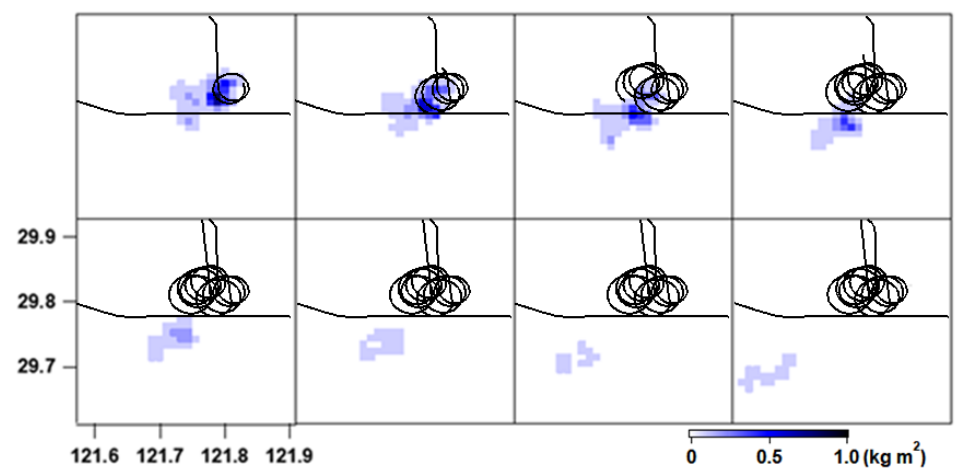

Figure S4. Vertical integration liquid water content (VIL, consider 5 layers grids data at 1000 3000m intervals of $500 \mathrm{~m}$ ) of seeding echo at 0336 0418 UTC (6 min intervals).

\section{Reference}

Bian, J., Chen, H., Vömel, H., Duan, Y., Xuan, Y., and Lü, D.: Intercomparison of humidity and temperature sensors: GTS1, Vaisala RS80, and CFH, Advances in Atmospheric Sciences, 28, 139-146, 2011.

Chernykh, I. V., and Eskridge, R. E.: Determination of cloud amount and level from radiosonde soundings, Journal of applied meteorology, 35, 1362-1369, 1996.

Guo, J., Miao, Y., Zhang, Y., Liu, H., Li, Z., Zhang, W., He, J., Lou, M., Yan, Y., and Bian, L.: The climatology of planetary boundary layer height in China derived from radiosonde and reanalysis data, Atmospheric Chemistry and Physics, 16, 13309, 2016.

Li, W., Xing, Y., and Ma, S.: The analysis and comparison between GTS1 radiosonde made in China and RS92 Radiosonde of Vaisala company, Meteorological Monthly (in Chinese), 35, 97-102, 2009.

Poore, K. D., Wang, J., and Rossow, W. B.: Cloud layer thicknesses from a combination of surface and upper-air observations, Journal of Climate, 8, 550-568, 1995. 
Tuttle, J. D., and Foote, G. B.: Determination of the boundary layer airflow from a single Doppler radar, Journal of Atmospheric and oceanic Technology, 7, 218-232, 1990.

Wang, J., and Rossow, W. B.: Determination of cloud vertical structure from upper-air observations, Journal of Applied Meteorology, 34, 2243-2258, 1995.

Wang, J., Rossow, W. B., Uttal, T., and Rozendaal, M.: Variability of cloud vertical structure during ASTEX observed from a combination of rawinsonde, radar, ceilometer, and satellite, Monthly weather review, 127, 2484-2502, 1999.

Zhang, J., Chen, H., Li, Z., Fan, X., Peng, L., Yu, Y., and Cribb, M.: Analysis of cloud layer structure in Shouxian, China using RS92 radiosonde aided by $95 \mathrm{GHz}$ cloud radar, Journal of Geophysical Research: Atmospheres, 115, 2010.

Zhang, W., Guo, J., Miao, Y., Liu, H., Zhang, Y., Li, Z., and Zhai, P.: Planetary boundary layer height from CALIOP compared to radiosonde over China, Atmospheric Chemistry and Physics, 16, 9951-9963, 2016.

Zhou, Y., and Ou, J.: The method of cloud vertical structure analysis using rawinsonde observation and its applied research, Meteor. Mon, 36, 50-58, 2010. 